\title{
Inhibition of human TREK-1 channels by caffeine and theophylline
}

\author{
S. Harinath, S.K. Sikdar* \\ Molecular Biophysics Unit, Indian Institute of Science, Bangalore 560012, India
}

\begin{abstract}
Caffeine (1,3,7-trimethylxanthine) and theophylline (1,3-dimethylxanthine) are used for therapeutic purposes and can cause life-threatening convulsive seizures due to systemic toxicity. The mechanisms for the epileptogenicity of caffeine and theophylline are not clear. TWIK-related $\mathrm{K}^{+}$channels (TREK-1) are highly expressed in the human central nervous system and have a major role in the control of neuronal excitability by regulating the resting membrane potential. In view of their physiological significance, inhibition of TREK-1 channels may be implicated in caffeine- and theophylline-induced seizures. We thus investigated, using whole-cell patch-clamp technique, modulation of hTREK-1 channels expressed in Chinese hamster ovary (CHO) cells by caffeine and theophylline. Caffeine and theophylline produced reversible inhibition of TREK-1 channels in a concentration-dependent manner. The half-maximal inhibitory concentrations $\left(\mathrm{IC}_{50}\right)$ for caffeine and theophylline were $377 \pm 54 \mu \mathrm{M}$ and $486 \pm 76 \mu \mathrm{M}$, respectively. Caffeine and theophylline depolarized the membrane potential of $\mathrm{CHO}_{\mathrm{TREK}-1}$ cells in a reversible and concentrationdependent manner. Inhibition by caffeine $(5 \mathrm{mM})$ and theophylline $(2 \mathrm{mM})$ was attenuated in TREK-1 channels with mutation of the PKA consensus sequence at serine 348, suggesting the involvement of cAMP/PKA pathway in the inhibitory process. Inhibition of TREK-1 channels and consequent membrane depolarization may contribute to the convulsive seizures induced by toxic levels of caffeine and theophylline.
\end{abstract}

Keywords: Caffeine; Theophylline; Seizures; TREK-1 channel; Whole-cell patch-clamp

\section{Introduction}

Caffeine (1,3,7-trimethylxanthine) and theophylline (1,3-dimethylxanthine) are chemically closely related xanthine alkaloids that are present in appreciable concentrations in common beverages such as coffee, tea

\footnotetext{
* Corresponding author. Tel.: +91 8022933220 ; fax: +91 8023600535 .

E-mail address: sks@mbu.iisc.ernet.in (S.K. Sikdar).
}

and soft drinks. Caffeine and theophylline are frequently used in the treatment and prevention of neonatal apnea, and theophylline is used in prophylactic therapy for asthma (Shannon, 1999; Carrillo and Benitez, 2000). Overdoses of caffeine and theophylline are associated with convulsive seizures (Banner and Czajka, 1980; Chu, 1981; Davis et al., 1986; Ramzan and Levy, 1986; Dietrich and Mortensen, 1990; Shum et al., 1997; Shannon, 1999; Carrillo and Benitez, 2000). The mechanism of convulsions produced by caf- 
feine and theophylline is, however, still unclear. Antagonism of adenosine receptors has been presumed to contribute to the convulsions (Dunwiddie, 1985; Dragunow et al., 1987). Other reports have suggested that these convulsions may be due to block of inhibitory neurotransmitter receptors $\left(\mathrm{GABA}_{\mathrm{A}}\right.$ and glycine receptors) and enhancement of NMDA receptor neurotransmission (Uneyama et al., 1993; Amabeoku, 1999).

Two pore-domain potassium channels are the recently identified novel family of potassium channels $\left(\mathrm{K}_{2 \mathrm{P}}\right)$ (Lesage and Lazdunski, 2000; Goldstein et al., 2001), and classified as background potassium channels or leak potassium channels. These channels are the major determinants of the resting membrane potential, and exert control over neuronal excitability through their influence on the resting membrane potential. Enhanced leak channel activity hyperpolarizes neurons, leading to decreased action potential firing; in contrast, leak suppression results in membrane depolarization and excitation (Sirois et al., 2000). TREK-1 is an important member of this family, and is expressed through out the central nervous system (Fink et al., 1996; Lauritzen et al., 2000; Hervieu et al., 2001; Medhurst et al., 2001; Talley et al., 2001). TREK-1 has been proposed to be an important pharmacological target for general anesthetics (Franks and Honore, 2004). Recent experiments using knockout mice provided direct evidence for a role for TREK-1 in neuroprotection, anesthesia and the control of epileptogenesis (Heurteaux et al., 2004). We hypothesized that the epileptogenicity of caffeine and theophylline is related to the inhibition of TREK-1 channels. We investigated this possibility by examining whether caffeine and theophylline modulate hTREK-1 channels expressed heterologously in Chinese hamster ovary cells.

\section{Methods}

\subsection{Cell culture and transfection}

A stable cell-line of $\mathrm{CHO}$ cells expressing human TREK-1 channels $\left(\mathrm{CHO}_{\text {TREK-1}}\right.$; Harinath and Sikdar, 2004) was maintained in DMEM-F-12 HAM supplemented with $10 \%$ fetal bovine serum $(\mathrm{v} / \mathrm{v})$, $1 \%$ antibiotic-antimycotic (Sigma) and gentamicin $(50 \mu \mathrm{g})$ (Sigma) in a humidified incubator with an atmosphere of $5 \% \mathrm{CO}_{2}$. When the cells were confluent, they were split and plated onto $35 \mathrm{~mm}$ culture dishes. The cells were used after 2 days for electrophysiological recordings.

Unlike the wild type hTREK-1, the S348A mutant of hTREK-1 was transiently expressed in $\mathrm{CHO}$ cells by the classical calcium phosphate precipitation method. As a marker of successful transfection cells were co-transfected with EGFP (green fluorescent protein) (Clontech). DNA calcium-phosphate precipitate was made as follows. In a $1.5 \mathrm{ml}$ sterile microcentrifuge tube, $2 \mu \mathrm{g}$ of S348A hTREK-1 cDNA, $1 \mu \mathrm{g}$ of EGFP and $110 \mu \mathrm{l}$ of sterile water were mixed, to that $15 \mu \mathrm{l}$ of $2.5 \mathrm{M} \mathrm{CaCl}_{2}$ was added and thoroughly mixed. Then, $0.25 \mathrm{ml}$ of $2 \times$ HBS was taken in another $1.5 \mathrm{ml} \mathrm{mi-}$ crocentrifuge tube, and the DNA- $\mathrm{CaCl}_{2}$ mixture was added to it slowly dropwise, while bubbling air in the solution with a Pasteur pipette. The whole mixture was vortexed for $30 \mathrm{~s}$ immediately, and allowed to stand at room temperature for $20 \mathrm{~min}$. After $20 \mathrm{~min}$, a very fine precipitate was seen in the tube, and with a Pasteur pipette the precipitate was evenly distributed onto $35 \mathrm{~mm}$ culture dish with attached $\mathrm{CHO}$ cells. Cells were incubated with the precipitate for $4 \mathrm{~h}$ in the incubator. The medium was then removed and the cells were subjected to a glycerol shock, followed by three washes with PBS. Finally, the cells were fed with fresh medium and returned to the incubator. After $48 \mathrm{~h}$ of transfection, green fluorescence from cells expressing EGFP was detected using standard FITC filter set with xenon light excitation. Cells showing green fluorescence could be reliably observed although they were plated on plastic dishes, and were chosen for electrophysiological recordings.

\subsection{Electrophysiology and drug application}

Membrane currents were recorded in whole-cell configuration using patch pipettes. Pipettes with tip resistance of 3-5 $\mathrm{M} \Omega$ were used for recordings. The external solution contained in $\mathrm{mM}: \mathrm{NaCl}, 150 ; \mathrm{KCl}, 5$; $\mathrm{MgCl}_{2}, 1 ; \mathrm{CaCl}_{2}, 1 ;$ HEPES, 10; pH 7.4 with $\mathrm{NaOH}$. The patch-pipette solution contained in $\mathrm{mM}: \mathrm{KCl}, 150$; $\mathrm{MgCl}_{2}$, 1; EGTA, 5; HEPES, 10; pH 7.2 with $\mathrm{KOH}$. An EPC 8 patch-clamp amplifier (HEKA) was used to record membrane currents. Before seal formation, the voltage offset between the patch electrode and the bath solution was adjusted to produce zero current. Pulse software (HEKA) was used to generate voltage-clamp 
protocols and acquire data. The holding potential during experiments was $-80 \mathrm{mV}$. All recordings were performed at $25^{\circ} \mathrm{C}$. Cells were continuously perfused with external solution at a rate of approximately $1 \mathrm{ml} / \mathrm{min}$ through out the experiments using a peristaltic pump. Perfusion with bathing solution alone had no effect on current amplitudes. Caffeine (Sigma) and theophylline (Spectrochem, India) were dissolved in the extracellular medium to the desired concentration just before use. Drug solutions were applied rapidly to the cell by pressure ejection (PLI-100, Medical Systems Corp) from a large tipped pipette that was positioned close to the cell with a micromanipulator.

\subsection{Data analysis}

Sigma plot was used for data analysis. For dose-response experiments, current amplitudes at $0 \mathrm{mV}$ during the presence and in the absence of caffeine were measured, by evoking the currents with a ramppulse protocol from -100 to $+60 \mathrm{mV}$ over $300 \mathrm{~ms}$ duration. To obtain concentration-response curves, the percent inhibition of the currents (at a membrane potential of $0 \mathrm{mV}$ ) by caffeine and theophylline were quantified at various test concentrations according to the following equation, percent inhibition $=100(1-$ $\left.I_{\text {drug }} / I_{\text {control }}\right)$. The concentration-response data were fitted by Hill equation of the form $y=\left(a x^{\mathrm{b}}\right) /\left(c^{\mathrm{b}}+x^{\mathrm{b}}\right)$; where $y=$ inhibition, $x=$ drug concentration, $a=\max -$ imal inhibition, $b=$ Hill coefficient, $c=$ half-maximal inhibitory concentration or $\mathrm{IC}_{50}$ value. GraphPad software was utilized for performing statistical tests. Statistical significance was assessed using Wilcoxon test for paired data and Mann-Whitney test for unpaired data. All data are expressed as mean \pm S.E.M.

\section{Results}

In our previous report we described the stable expression of human TREK-1 in CHO cells (Harinath and Sikdar, 2004). We utilized the same cell-line for experiments in the present study. As a first test for the presence of TREK-1 channels, we measured the resting membrane potential of $\mathrm{CHO}_{\text {TREK-1 }}$ cells under physiological conditions. $\mathrm{CHO}_{\text {TREK-1 }}$ cells had resting membrane potentials of $-74 \pm 1 \mathrm{mV}(n=11)$. Wild-type $\mathrm{CHO}$ cells had resting membrane potentials of $-15 \pm 6.5 \mathrm{mV}(n=7)$. $\mathrm{CHO}_{\text {TREK-1 }}$ cells also displayed large outward currents with an instantaneous and a time-dependent component upon depolarization (Fig. 1A), which were absent in wild-type $\mathrm{CHO}$ cells. At a test potential of $0 \mathrm{mV}, \mathrm{CHO}_{\text {TREK-1 }}$ cells had current amplitudes of $785.48 \pm 138.7 \mathrm{pA}(n=24)$, which were significantly greater than those recorded from wild-type CHO cells, $16.14 \pm 4.86 \mathrm{pA}(n=5)$ $(P<0.001$, Mann-Whitney test).

To investigate if caffeine could modulate recombinant hTREK-1 channels, $\mathrm{CHO}_{\text {TREK-1 }}$ cells were exposed to caffeine as follows. Immediately after establishing whole-cell clamp, control recordings were taken and then caffeine was applied rapidly to the cell by pressure ejection (see Section 2.2) for at least 2-3 min. After measuring the current amplitudes during application of caffeine, the cell was washed. Fig. 1A illustrates an experiment where hTREK-1 currents were elicited by depolarizing voltage steps from a holding potential of $-80 \mathrm{mV}$ before, during and after $750 \mu \mathrm{M}$ caffeine application. Caffeine produced inhibition of hTREK- 1 currents at all the test potentials and the inhibition was fully reversible. To test the ion selectivity of the current inhibited by caffeine, membrane was ramped from -100 to $+60 \mathrm{mV}$. Whole-cell ramp currents as a function of membrane potential before and during caffeine application are shown in Fig. 1B. Caffeine inhibited a $\mathrm{K}^{+}$selective current that reversed close to a value $(-87 \mathrm{mV})$ predicted by the Nernst equation for a purely potassium-selective channel. The effect of caffeine on hTREK-1 currents was studied at concentrations of $0.1,0.75,2,5$ and $10 \mathrm{mM}$. At a concentration of $750 \mu \mathrm{M}$, caffeine caused a $60.17 \pm 3.44 \%(n=7)$ reduction in current amplitude at $0 \mathrm{mV}$ from control. Caffeine caused dose-dependent inhibition of hTREK1 channels (Fig. 1C). The concentration-response data were mathematically described by a Hill equation with an $\mathrm{IC}_{50}$ of $377 \pm 54 \mu \mathrm{M}$. Fig. $2 \mathrm{~A}$ shows a time-series plot obtained from the current amplitude measurements at $0 \mathrm{mV}$ evoked by ramping the membrane from -100 to $+60 \mathrm{mV}$ ( $300 \mathrm{~ms}$ duration) for every $5 \mathrm{~s}$. Inhibition was gradual and usually reached a maximum after 2-3 min of sustained caffeine exposure. Upon washing the cell, inhibition was completely reversible in few minutes. Inhibition of TREK-1 channels is expected to depolarize the cell membrane. Consistent with this, perfusion of $\mathrm{CHO}_{\text {TREK-1 }}$ cells with caffeine caused reversible depolarization of the cell membrane 

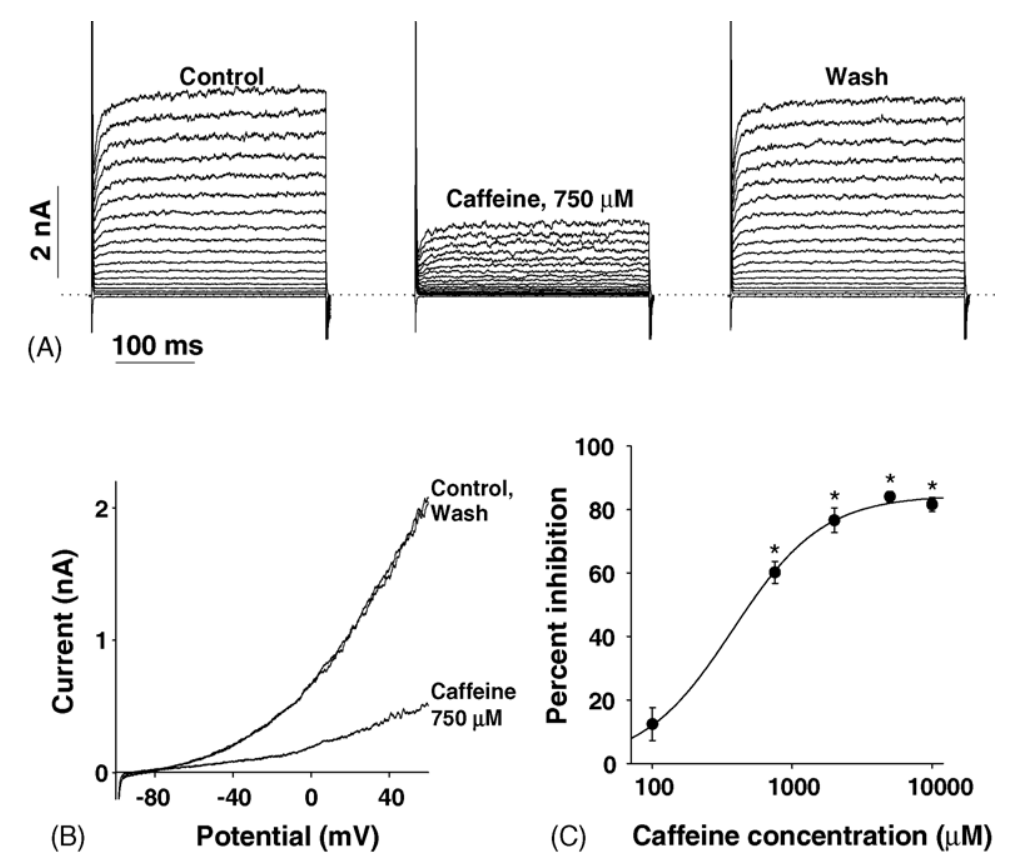

Fig. 1. Caffeine inhibits human TREK-1 outward currents. (A) Sample whole-cell currents before, during and after application of $750 \mu \mathrm{M}$ caffeine. Holding potential was $-80 \mathrm{mV}$ and currents were evoked using rectangular $300 \mathrm{~ms}$ voltage pulses from -90 to $100 \mathrm{mV}$ in steps of $10 \mathrm{mV}$. Caffeine inhibition of hTREK-1 was reversible with washout. (B) Whole-cell ramp currents as a function of membrane potential before, during and after caffeine $(750 \mu \mathrm{M})$ application. Caffeine inhibited a $\mathrm{K}^{+}$-selective current that reversed close to a value $(-87 \mathrm{mV})$ predicted by the Nernst equation for a purely potassium-selective channel. Currents were evoked from a holding potential of $-80 \mathrm{mV}$ by ramping the membrane from -100 to $+60 \mathrm{mV}$ over $300 \mathrm{~ms}$ duration. (C) Concentration-response curve for caffeine inhibition of hTREK-1 currents at $0 \mathrm{mV}$. Data were fitted to a Hill equation (see Section 2.3) and the $\mathrm{IC}_{50}$ (half-maximal inhibitory concentration) was $377 \pm 54 \mu \mathrm{M}$. Each point represents the mean \pm S.E.M. of $n=4-7$ cells. ${ }^{*} P<0.05$ compared to control (Wilcoxon test).

(Fig. 2B). The depolarization induced by caffeine was concentration-dependent (Fig. 2C). At a concentration of $750 \mu \mathrm{M}$, caffeine caused a $10.7 \pm 2 \mathrm{mV}(n=10)$ membrane depolarization.

Theophylline, a caffeine-related compound, also caused reversible inhibition of hTREK-1 channels (Fig. 3A). The effect of theophylline on hTREK-1 currents was studied at concentrations of $0.1,0.5$, 1 and $2 \mathrm{mM}$. At a concentration of $500 \mu \mathrm{M}$, theophylline caused a $44.3 \pm 4 \%(n=7)$ reduction in current amplitude at $0 \mathrm{mV}$ from control. Theophylline caused dose-dependent inhibition of hTREK-1 channels (Fig. 3B). The concentration-response data for theophylline were mathematically described by a Hill equation with an $\mathrm{IC}_{50}$ of $486 \pm 76 \mu \mathrm{M}$. Similar to caffeine, inhibition was gradual and usually reached a maximum after $2-4$ min of sustained theophylline exposure. Theophylline induced reversible depolarization of $\mathrm{CHO}_{\text {TREK-1 }}$ cells in a dose- dependent fashion (Fig. 3C). At a concentration of $500 \mu \mathrm{M}$, theophylline caused an $8 \pm 1.2 \mathrm{mV}$ membrane depolarization.

To confirm that the membrane depolarization of $\mathrm{CHO}_{\text {TREK-1 }}$ cells induced by caffeine and theophylline is related to the inhibition of hTREK-1 channels, we investigated the effects of caffeine and theophylline on the resting membrane potential of wild-type $\mathrm{CHO}$ cells. Caffeine $(2 \mathrm{mM})$ and theophylline $(2 \mathrm{mM})$ failed to cause membrane depolarization of the wild-type CHO cells $(n=4$ each). We also checked the effects of caffeine $(n=5)$ and theophylline $(n=3)$ after hyperpolarizing wild-type $\mathrm{CHO}$ cells towards potentials $(\sim$ $-74 \mathrm{mV}$ ) close to the resting potential of $\mathrm{CHO}_{\text {TREK-1 }}$ cells. Under this condition no clear-cut membrane depolarization of the wild-type $\mathrm{CHO}$ cells with caffeine and theophylline applications was seen.

Previous studies have shown that TREK-1 activity is down modulated by cAMP/PKA pathway (Patel 

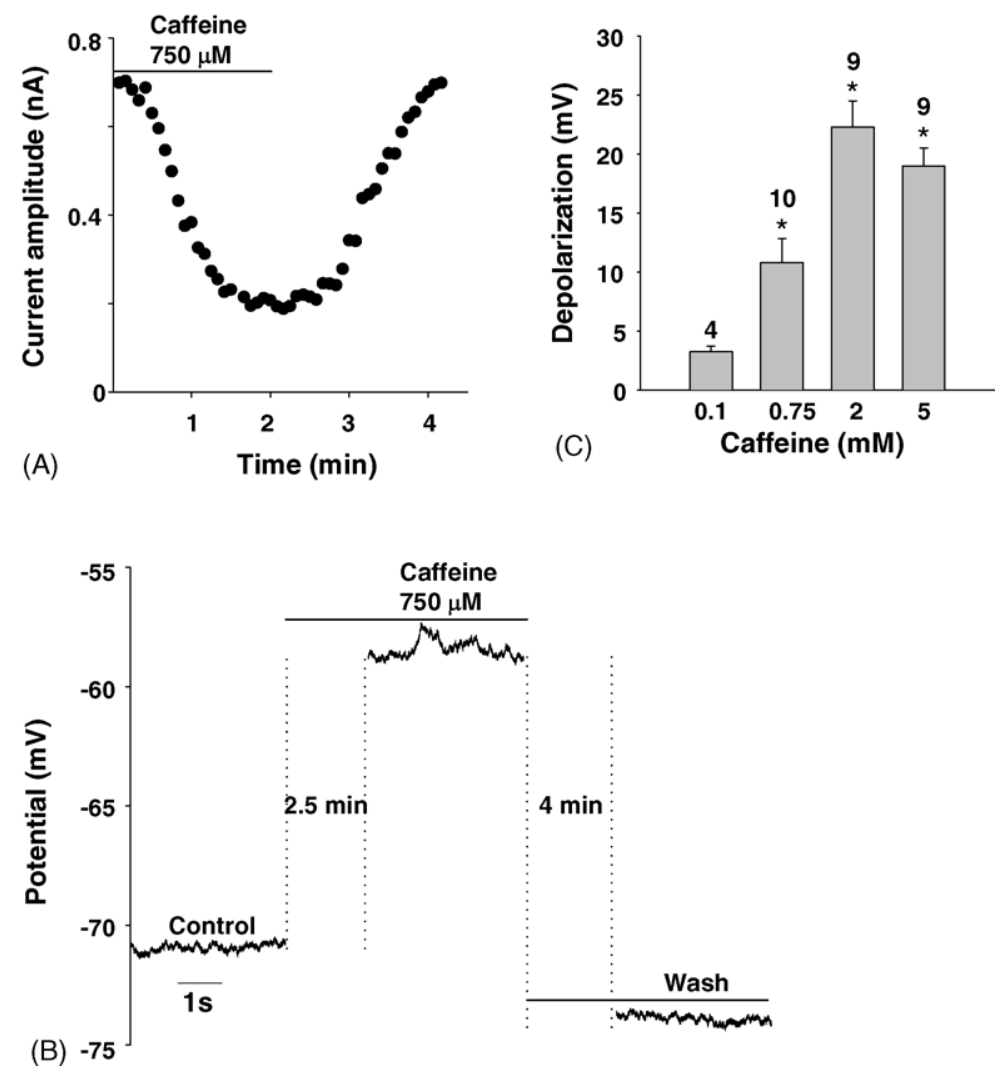

Fig. 2. Effect of caffeine on the membrane potential of $\mathrm{CHO}_{\text {TREK-1 }}$ cells. (A) A typical time-series plot for inhibition of hTREK-1 channel by caffeine obtained from the current amplitude measurements at $0 \mathrm{mV}$ evoked by ramping the membrane from -100 to $+60 \mathrm{mV}$ ( $300 \mathrm{~ms}$ duration) for every $5 \mathrm{~s}$. Inhibition was gradual and reached a maximum after $2 \mathrm{~min}$ of sustained caffeine exposure. Inhibition was fully reversible in about $2 \mathrm{~min}$, upon washing the cell. Solid line indicates the duration of caffeine application. (B) Original recordings of the membrane potential of $\mathrm{CHO}_{\text {TREK-1 }}$ cell under control condition, during application of caffeine $(750 \mu \mathrm{M})$, and after washout of the drug. Caffeine application was for about 2.30 min. Caffeine-induced depolarization of the membrane was reversible on washout. (C) The histogram summarizes the dose-dependent depolarization of $\mathrm{CHO}_{\text {TREK-1 }}$ cells by caffeine. Number of different cells tested for each concentration is indicated at the top of the bar. ${ }^{*} P<0.01$ compared to control (Wilcoxon test).

et al., 1998). Phosphorylation of S333 located at the distal end of the $\mathrm{C}$-terminal cytoplasmic tail is responsible for cAMP-mediated inhibition of TREK-1 (Patel et al., 1998). Since methylxanthines including caffeine and theophylline inhibit phosphodiesterase activity, leading to a gradual increase in intracellular cAMP, we assessed the involvement of cAMP/PKA pathway in the inhibitory action of caffeine and theophylline. The hTREK-1 channel employed in this study has an extension of 15 amino acids in the amino terminus and hence the corresponding residue for cAMP regulation in our sequence is S348. Inhibition by caffeine and theophylline was attenuated in hTREK-1 channels with mutation of the PKA consensus sequence at serine 348 (to alanine), suggesting the involvement of cAMPdependent phosphorylation in the inhibitory process (Fig. 4A-D).

\section{Discussion}

TREK-1 channels are the physiological correlates of potassium leak currents and control the excitability of neurons by regulating the resting membrane potential. TREK-1 channels are highly expressed in the human CNS (Medhurst et al., 2001) and are targets for 

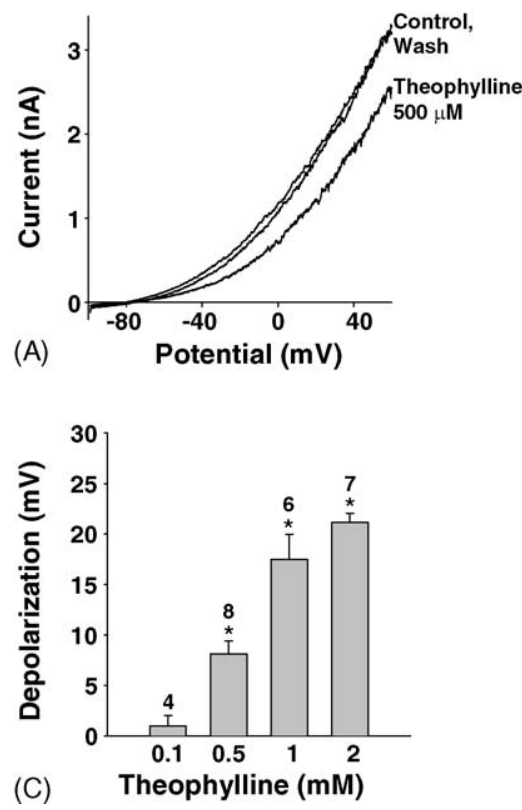

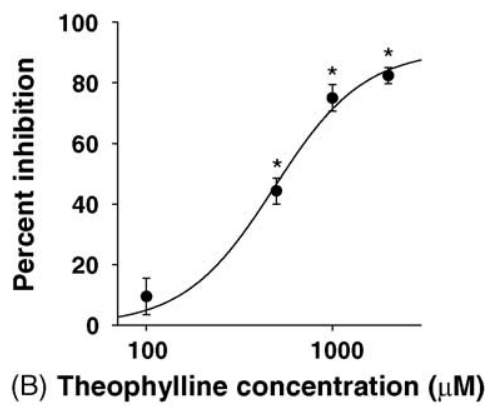

(B) Theophylline concentration $(\mu \mathrm{M})$

Fig. 3. Inhibitory effect of theophylline on human TREK-1 currents. (A) Whole-cell ramp currents as a function of membrane potential before, during and after theophylline $(500 \mu \mathrm{M})$ application. Theophylline inhibited a $\mathrm{K}^{+}$-selective current that reversed close to a value $(-87 \mathrm{mV})$ predicted by the Nernst equation for a purely potassium-selective channel. Currents were evoked from a holding potential of $-80 \mathrm{mV}$ by ramping the membrane from -100 to $+60 \mathrm{mV}$ over $300 \mathrm{~ms}$ duration. (B) Concentration-response curve for theophylline inhibition of hTREK-1 currents at $0 \mathrm{mV}$. Data were fitted to a Hill equation (see Section 2.3) and the $\mathrm{IC}_{50}$ (half-maximal inhibitory concentration) was $486 \pm 76 \mu \mathrm{M}$. Each point represents the mean \pm S.E.M. of $n=4-7$ cells. ${ }^{*} P<0.05$ compared to control (Wilcoxon test). (C) The histogram summarizes the dose-dependent depolarization of $\mathrm{CHO}_{\text {TREK-1 }}$ cells by theophylline. Number of different cells tested for each concentration is indicated at the top of the bar. ${ }^{*} P<0.05$ compared to control (Wilcoxon test).

pharmacologically important compounds like general anesthetics and neuroprotective drugs like riluzole (Franks and Honore, 2004). TREK-1 is potently inhibited by neurotransmitters that produce an increase in intracellular cAMP and also by those that activate the Gq protein pathway suggesting that probably TREK-1 channels have a central role in the control of excitability by neurotransmitters (Patel et al., 1998; Chemin et al., 2003). Recent in vivo evidence points to TREK-1 as a key target for epileptogenesis. TREK-1 ${ }^{-1-}$ mice displayed an increased sensitivity to epileptic agents, kainate and pentylenetetrazol (Heurteaux et al., 2004). Our results show that both caffeine and theophylline inhibit hTREK-1 channels and depolarize cells expressing hTREK-1 channels. Extension of these results to the in vivo situation would imply that inhibition of TREK-1 channels might be one of the ionic mechanisms underlying the convulsant actions of caffeine and theophylline, through significant increase in neuronal excitability.

During caffeine intoxication, plasma concentrations may reach up to $1-2 \mathrm{mM}$ (Carrillo and Benitez, 2000; Sardao et al., 2002). Dietrich and Mortensen (1990) reported a patient suffering from acute caffeine overdose, including seizures with a blood caffeine concentration of around $2 \mathrm{mM}$. Individuals with reduced caffeine elimination or metabolization may achieve such toxic concentrations. In this particular matter, neonates appear to be particularly susceptible to caffeine intoxication, not only by having half-lives for caffeine elimination much higher than adults, but also by having a much smaller absolute volume of distribution (Carrillo and Benitez, 2000; Sardao et al., 2002). There are clinically significant pharmacokinetic interactions that may substantially raise the plasma level of caffeine during concomitant administration of caffeine and 

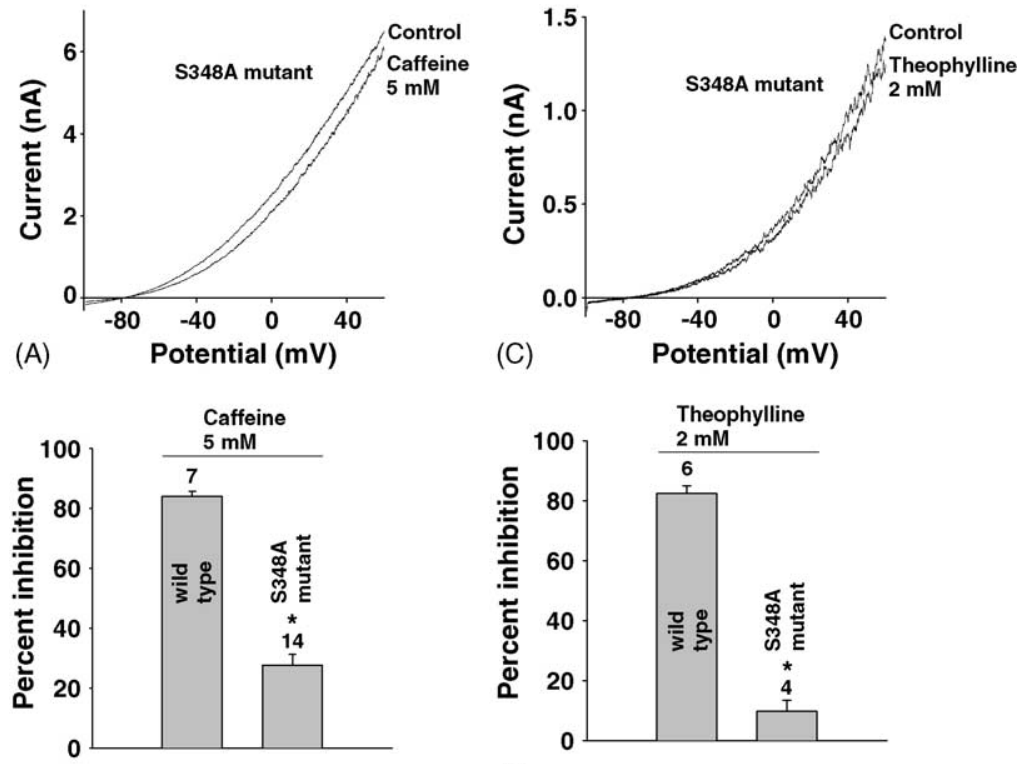

(B)

(D)

Fig. 4. Effect of caffeine and theophylline on CHO cells transiently expressing S348A mutant hTREK-1 channels. (A) Control ramp current and current recorded in the presence of caffeine as a function of membrane potential. Mutant channels showed markedly reduced inhibition to caffeine $(5 \mathrm{mM})$. Currents were evoked from a holding potential of $-80 \mathrm{mV}$ by ramping the membrane from -100 to $+60 \mathrm{mV}$ over $300 \mathrm{~ms}$ duration. (B) The histogram summarizes the effect of caffeine $(5 \mathrm{mM})$ on both wild type and mutant (S348A) hTREK-1 channels. Number of different cells tested is indicated at the top of the bar. ${ }^{*} P<0.001$ compared to wild-type hTREK-1 (Mann-Whitney test). (C) Control ramp current and current recorded in the presence of theophylline as a function of membrane potential. Mutant channels showed markedly reduced inhibition to theophylline $(2 \mathrm{mM})$. Currents were evoked from a holding potential of $-80 \mathrm{mV}$ by ramping the membrane from -100 to $+60 \mathrm{mV}$ over $300 \mathrm{~ms}$ duration. (D) The histogram summarizes the effect of theophylline $(2 \mathrm{mM})$ on both wild type and mutant (S348A) hTREK-1 channels. Number of different cells tested is indicated at the top of the bar. ${ }^{*} P<0.01$ compared to wild-type hTREK-1 (Mann-Whitney test).

certain medications (Carrillo and Benitez, 2000). There is no blood-brain barrier to caffeine in the adult or the fetal animal (Fredholm et al., 1999). In newborn infants, caffeine concentration is similar in plasma and cerebrospinal fluid (CSF) (Fredholm et al., 1999). Shannon (1999) found patients with theophylline overdose, had serum theophylline concentrations ranging from 167 to $1360 \mu \mathrm{M}$. In elderly patients, there are several risk factors that may increase the plasma theophylline level, such as reduced clearance, various underlying diseases and pharmacokinetic drug-drug interactions (Ohnishi et al., 2003). For theophylline, however, there is a blood-brain barrier and the reported brain:blood concentration ratio for theophylline in the adult rat is 0.41 (Arnaud et al., 1982). Auritt et al. (1985) reported CSF:plasma ratio of 0.41 for theophylline in adolescents. Steady state brain:plasma ratios, CSF:plasma ratios for theophylline in neonatal rats are significantly higher than the ratios in adult rats. The reported brain:blood ratios in neonatal rats are between 0.76 and 0.87 (Habgood et al., 1998). Based on data from Auritt et al. (1985) (considering CSF:plasma ratio of 0.41) and Shannon (1999) (serum theophylline concentrations, $167-1360 \mu \mathrm{M})$, the estimated theophylline concentrations in the CSF during toxicity may reach up to $557 \mu \mathrm{M}$. Since there is greater penetration of theophylline from blood into brain and CSF in the neonatal rats (Habgood et al., 1998), the concentrations that reach in the CSF during toxicity might be greater in the case of neonates. Using an animal model of theophylline-induced seizures, Ramzan and Levy (1986) reported theophylline concentrations of $\sim 1190$ to $1380 \mu \mathrm{M}$ in the cerebrospinal fluid of adult rat. The observed IC $_{50}$ values for hTREK1 inhibition by caffeine and theophylline in this study are well within the concentrations that are achievable 
with caffeine and theophylline intoxication. Thus, it is likely that inhibition of TREK-1 channels may contribute to the convulsions caused by caffeine and theophylline.

There have been reports describing effects of caffeine and theophylline on potassium currents. Caffeine has been reported to inhibit potassium channels in a number of cell types, including mammalian ventricular myocytes (Sanchez-Chapula, 1992; Varro et al., 1993; Cui and Terrar, 1995; Chorvatova and Hussain, 2003), smooth muscle cells (Noack et al., 1990; Teramoto et al., 2000), dissociated chick autonomic ganglion neurons and pineal cells (Reiser et al., 1996), taste receptor cells (Zhao et al., 2002) and rat anterior pituitary cells (Kramer et al., 1994). Theophylline, too, has been shown to modulate potassium channels (Yamamoto et al., 1995; Schroder et al., 2000). All these studies suggest, a direct action of caffeine and theophylline on potassium channels. Experiments with the mutant TREK-1 channel (S348A mutant) in the present study, suggested the involvement of cAMP/PKA pathway in the inhibition of TREK-1 channels by caffeine and theophylline (Fig. 4).

In conclusion, we demonstrated that both caffeine and theophylline dose-dependently inhibit hTREK-1 channels. Inhibition of TREK- 1 channels may increase membrane excitability that could contribute to the excitotoxic side effects of caffeine and theophylline.

\section{Acknowledgements}

We are grateful to Prof. Steve A.N. Goldstein (Yale University) for kindly providing hTREK-1 and S348A mutant of hTREK-1. We would also like to thank Bharat V. Adkar and Samrat Roy for technical assistance. The research was funded by grants from the Department of Science \& Technology, India.

\section{References}

Amabeoku, G.J., 1999. Gamma-aminobutyric acid and glutamic acid receptors may mediate theophylline-induced seizures in mice. Gen. Pharmacol. 32, 365-372

Arnaud, M.J., Bracco, I., Welsch, C., 1982. Metabolism and distribution of labeled theophylline in the pregnant rat. Impairment of theophylline metabolism by pregnancy and absence of a blood brain barrier in the fetus. Pediatr. Res. 16, 167-171.
Auritt, W.A., McGeady, S.J., Mansmann Jr., H.C., 1985. The relationship of cerebrospinal fluid and plasma theophylline concentrations in children and adolescents taking theophylline. J. Allergy Clin. Immunol. 75, 731-735.

Banner Jr., W., Czajka, P.A., 1980. Acute caffeine overdose in the neonate. Am. J. Dis. Child. 134, 495-498.

Carrillo, J.A., Benitez, J., 2000. Clinically significant pharmacokinetic interactions between dietary caffeine and medications. Clin. Pharmacokinet. 39, 127-153.

Chemin, J., Girard, C., Duprat, F., Lesage, F., Romey, G., Lazdunski, M., 2003. Mechanisms underlying excitatory effects of group I metabotropic glutamate receptors via inhibition of $2 \mathrm{P}$ domain $\mathrm{K}^{+}$ channels. EMBO J. 22, 5403-5411.

Chorvatova, A., Hussain, M., 2003. Effects of caffeine on potassium currents in isolated rat ventricular myocytes. Pflugers Arch. 446, $422-428$.

Chu, N., 1981. Caffeine-and aminophylline-induced seizures. Epilepsia 22, 85-94.

Cui, Y., Terrar, D.A., 1995. Effects of caffeine on background potassium current in isolated guinea pig ventricular myocytes. J. Cardiovasc. Pharmacol. 25, 691-695.

Davis, J.M., Metrakos, K., Aranda, J.V., 1986. Apnoea and seizures. Arch. Dis. Child. 61, 791-793.

Dietrich, A.M., Mortensen, M.E., 1990. Presentation and management of an acute caffeine overdose. Pediatr. Emerg. Care 6, 296-298.

Dragunow, M., Goddard, G.V., Laverty, R., 1987. Proconvulsant effects of theophylline on hippocampal afterdischarges. Exp. Neurol. 96, 732-735

Dunwiddie, T.V., 1985. The physiological role of adenosine in the central nervous system. Int. Rev. Neurobiol. 27, 63139.

Fink, M., Duprat, F., Lesage, F., Reyes, R., Romey, G., Heurteaux, C., Lazdunski, M., 1996. Cloning, functional expression and brain localization of a novel unconventional outward rectifier $\mathrm{K}^{+}$channel. EMBO J. 15, 6854-6862.

Franks, N.P., Honore, E., 2004. The TREK $\mathrm{K}_{2 \mathrm{P}}$ channels and their role in general anaesthesia and neuroprotection. Trends Pharmacol. Sci. 25, 601-608.

Fredholm, B.B., Battig, K., Holmen, J., Nehlig, A., Zvartau, E.E., 1999. Actions of caffeine in the brain with special reference to factors that contribute to its widespread use. Pharmacol. Rev. 51, 83-133.

Goldstein, S.A., Bockenhauer, D., O'Kelly, I., Zilberberg, N., 2001. Potassium leak channels and the KCNK family of two-P-domain subunits. Nat. Rev. Neurosci. 2, 175-184.

Habgood, M.D., Knott, G.W., Dziegielewska, K.M., Saunders, N.R., 1998. Permeability of the developing and mature blood-brain barriers to theophylline in rats. Clin. Exp. Pharmacol. Physiol. $25,361-368$.

Harinath, S., Sikdar, S.K., 2004. Trichloroethanol enhances the activity of recombinant human TREK-1 and TRAAK channels. Neuropharmacology 46, 750-760.

Hervieu, G.J., Cluderay, J.E., Gray, C.W., Green, P.J., Ranson, J.L., Randall, A.D., Meadows, H.J., 2001. Distribution and expression of TREK-1, a two-pore-domain potassium channel, in the adult rat CNS. Neuroscience 103, 899-919. 
Heurteaux, C., Guy, N., Laigle, C., Blondeau, N., Duprat, F., Mazzuca, M., Lang-Lazdunski, L., Widmann, C., Zanzouri, M., Romey, G., Lazdunski, M., 2004. TREK-1, a $\mathrm{K}^{+}$channel involved in neuroprotection and general anesthesia. EMBO J. 23, 2684-2695.

Kramer, R.H., Mokkapatti, R., Levitan, E.S., 1994. Effects of caffeine on intracellular calcium, calcium current and calcium dependent potassium current in anterior pituitary $\mathrm{GH}_{3}$ cells. Pflugers Arch. $426,12-20$.

Lauritzen, I., Blondeau, N., Heurteaux, C., Widmann, C., Romey, G., Lazdunski, M., 2000. Polyunsaturated fatty acids are potent neuroprotectors. EMBO J. 19, 1784-1793.

Lesage, F., Lazdunski, M., 2000. Molecular and functional properties of two pore domain potassium channels. Am. J. Physiol. Renal. Physiol. 279, F793-F801.

Medhurst, A.D., Rennie, G., Chapman, C.G., Meadows, H.J., Duckworth, M.D., Kelsell, R.E., Gloger, I.I., Pangalos, M.N., 2001. Distribution analysis of human two pore domain potassium channels in tissues of the central nervous system and periphery. Brain Res. Mol. Brain Res. 86, 101-114.

Noack, T., Deitmer, P., Golenhofen, K., 1990. Features of a calcium independent, caffeine sensitive outward current in single smooth muscle cells from guinea pig portal vein. Pflugers Arch. 416, 467-469.

Ohnishi, A., Kato, M., Kojima, J., Ushiama, H., Yoneko, M., Kawai, H., 2003. Differential pharmacokinetics of theophylline in elderly patients. Drugs Aging 20, 71-84.

Patel, A.J., Honore, E., Maingret, F., Leasge, F., Fink, M., Duprat, F., Lazdunski, M., 1998. A mammalian two pore domain mechanogated S-like $\mathrm{K}^{+}$channel. EMBO J. 17, 4283-4290.

Ramzan, I.M., Levy, G., 1986. Kinetics of drug action in disease states. XVI. Pharmacodynamics of theophylline-induced seizures in rats. J. Pharmacol. Exp. Ther. 236, 708-713.

Reiser, M.A., D'Souza, T., Dryer, S.E., 1996. Effects of caffeine and 3-isobutyl-1-methylxanthine on voltage-activated potassium currents in vertebrate neurones and secretory cells. Br. J. Pharmacol. $118,2145-2151$.

Sanchez-Chapula, J., 1992. Caffeine inhibits depolarizationactivated outward currents in rat ventricular myocytes. Eur. J. Pharmacol. 229, 163-169.
Sardao, V.A., Oliveira, P.J., Moreno, A.J.M., 2002. Caffeine enhances the calcium-dependent cardiac mitochondrial permeability transition: relevance for caffeine toxicity. Toxicol. Appl. Pharmacol. 179, 50-56.

Schroder, R.L., Jensen, B.S., Strobaek, D., Olesen, S.P., Christophersen, P., 2000. Activation of the human, intermediateconductance, $\mathrm{Ca}^{2+}$-activated $\mathrm{K}^{+}$channel by methylxanthines. Pflugers Arch. 440, 809-818.

Shannon, M., 1999. Life-threatening events after theophylline overdose: a 10-year prospective analysis. Arch. Intern. Med. 159, 989-994.

Shum, S., Seale, C., Hathaway, D., Chucovich, V., Beard, D., 1997. Acute caffeine ingestion fatalities: management issues. Vet. Hum. Toxicol. 39, 228-230.

Sirois, J.E., Lei, Q., Talley, E.M., Lynch III, C., Bayliss, D.A., 2000 The TASK-1 two-pore domain $\mathrm{K}^{+}$channel is a molecular substrate for neuronal effects of inhalation anesthetics. J. Neurosci. 20, 6347-6354.

Talley, E.M., Solorzano, G., Lei, Q., Kim, D., Bayliss, D.A., 2001. CNS distribution of members of the two-pore-domain (KCNK) potassium channel family. J. Neurosci. 21, 7491-7505.

Teramoto, N., Yunoki, T., Tanaka, K., Takano, M., Masaki, I., Yonemitsu, Y., Sueishi, K., Ito, Y., 2000. The effects of caffeine on ATP-sensitive $\mathrm{K}(+)$ channels in smooth muscle cells from pig urethra. Br. J. Pharmacol. 131, 505-513.

Uneyama, H., Harata, N., Akaike, N., 1993. Caffeine and related compounds block inhibitory aminoacid-gated $\mathrm{Cl}^{-}$currents in freshly dissociated rat hippocampal neurons. Br. J. Pharmacol. 109, 459-465.

Varro, A., Hester, S., Papp, J.G., 1993. Caffeine-induced decreases in the inward rectifier potassium and the inward calcium currents in rat ventricular myocytes. Br. J. Pharmacol. 109, 895-897.

Yamamoto, T., Kakehata, S., Yamada, T., Saito, T., Saito, H., Akaike, N., 1995. Caffeine rapidly decreases potassium conductance of dissociated outer hair cells of guinea-pig cochlea. Brain Res. 677, 89-96.

Zhao, F.L., Lu, S.G., Herness, S., 2002. Dual actions of caffeine on voltage-dependent currents and intracellular calcium in taste receptor cells. Am. J. Physiol. Regul. Integr. Comp. Physiol. 283, R115-R129. 